\title{
Isolation and Characterization of Exosomes from Mouse Feces
}

Chunhua Yang ${ }^{1, ~ *, ~ M i n g z h e n ~ Z h a n g ~}{ }^{1}$, Junsik Sung ${ }^{1}$, Lixin Wang ${ }^{1,2}$, Yunjin Jung ${ }^{1,3}$ and Didier Merlin ${ }^{1,2}$

${ }^{1}$ Institute for Biomedical Sciences, Center for Diagnostics and Therapeutics, Digestive Disease Research Group, Georgia State University, Atlanta, Georgia, 30302, United States; ${ }^{2}$ Atlanta Veterans Affairs Medical Center, Decatur, Georgia, 30033, United States; ${ }^{3}$ College of Pharmacy, Pusan National University, Busan, Republic of Korea

*For correspondence: cyang16@gsu.edu

[Abstract] Exosomes secreted by colonic epithelial cells are present in feces and contain valuable epigenetic information, such as miRNAs, proteins, and metabolites. An in-depth study of this information is conducive to the diagnosis or treatment of relevant diseases. A crucial prerequisite of such a study is to establish an efficient isolation method, through which we can obtain a relatively more significant amount of exosomes from feces. This protocol is designed to effectively isolate a large number of exosomes from contaminants and other particles in feces by a combined method with fast filtration and sucrose density gradient ultracentrifugation. Exosomes generated by this method are suitable for further RNA, protein, and lipid analysis.

Keywords: Colonic epithelial cells, Fecal exosomes, Isolation, Ultracentrifugation, Characterization

[Background] Colonic exosomes are secreted into the lumen by colonic epithelial cells, and they transit along the large intestine and present in feces. The lipid bilayer structure of these exosomes can prevent the degradation of encapsulated biomolecules (such as miRNAs) from complex conditions (as in feces) (Koga et al., 2011; Deng et al., 2013). This protective function of exosomes is especially useful, as these protected contents can be used to diagnose the diseases, such as colitis and colonic cancer. Importantly, reengineered exosomes can also efficiently deliver therapeutic biomolecules to some specific disease targets without generating immune toxicity to the host (Sun et al., 2010; Johnsen et al., 2014; Wang et al., 2016; Kim and Kim, 2018).

To date, exosomes have been successfully isolated from blood (Wu et al., 2017), urine (Knepper and Pisitkun, 2007; Motamedinia et al., 2016), cultured cell (Yeo et al., 2013), and tissue samples (GallartPalau et al., 2016; Vella et al., 2017). However, the isolation and characterization of exosomes from feces remain understudied, mainly because of their low abundance and the complexity of the biomatrix. Although few studies reported using CD63 conjugated immunomagnetic beads to isolate of exosome from feces (Koga et al., 2011), this method may not be able to capture a large number of exosomes for specific diagnostic studies, such as the metabolomics analysis, not to mention furthering the drug delivery studies. Contrarily, our protocol enables the production of a relatively large amount of exosomes and is suitable for further RNA, protein, and lipid analysis (Yang et al., 2019). 


\section{Materials and Reagents}

1. Powder-free gloves (Denville Scientific, catalog number: G4162)

2. Disposable spatulas (VWR, catalog number: 80081-194)

3. $50 \mathrm{ml}$ conical tubes (Denville Scientific, catalog number: C1062-P (1000799))

4. Sterilized glass funnel, $50 \mathrm{~mm}$ (Pyrex)

5. Scissor

6. Metal forceps

7. Filter paper, Medium/Fast flow (VWR ${ }^{\circledR}$, Grade 417, catalog number: 28313-068)

8. $50 \mathrm{ml}$ vacuum-driven filtration system (Steriflip ${ }^{\circledR}$, Millipore, $0.22 \mu \mathrm{m}$ pore size, catalog number: SCGP00525)

9. BioLite 96-well plate (Thermo Fisher Scientific, catalog number: 12-556-008)

10. Nitrocellulose membranes/filter paper (Bio-Rad, catalog number: 1620215)

11. Pipettes (Eppendorf, 2.5, 10, 20, 100, 200, and 1, $000 \mu \mathrm{l}$ )

12. Formvar ${ }^{\circledR}$-coated copper grids (Electron Microscopy Sciences, catalog number: FCF300-CU$\mathrm{SC})$

13. Mica sheet (Electron Microscopy Sciences, catalog number: 71855-15)

14. Regular pipette tips

15. Paper towels

16. $130 \mathrm{oz}$ paper buckets with $215 \mathrm{~mm}$ lids (Karat, catalog number: C-FB130W)

17. Basic mouse cage assembly includes an internal water bottle (Optimice ${ }^{\circledR}$, catalog number: C79100 M/P/S)

18. Anti-CD63, rat anti-mouse (BD Biosciences, catalog number: 564221)

19. Bovine serum albumin (Sigma-Aldrich, catalog number: A2153-10G)

20. Pre-stained protein standards, 10-250 KD (Precision Plus Protein ${ }^{\mathrm{TM}}$, Bio-Rad, catalog number: 1610373)

21. Non-fat milk (Sigma-Aldrich, catalog number: M7409-1BTL)

22. Sodium dodecyl sulfate (SDS) powder (BIO-RAD, catalog number: 1610301)

23. Glycine (Sigma-Aldrich, catalog number: 50046-50G)

24. Roche protease inhibitor cocktail, tablets (Sigma-Aldrich, catalog number: 4693159001)

25. Sucrose (Calbiochem ${ }^{\circledR}$, Millipore, catalog number: $573113-1 K G$ )

26. Ponceau S solution (Sigma-Aldrich, catalog number: P7170-1L)

27. DC ${ }^{\mathrm{TM}}$ Protein assay reagent kit II (Bio-Rad, catalog number: 500-0002)

28. Phosphate-Buffered Saline (PBS) (Corning, catalog number: 21-040-CV)

29. RIPA Lysis Buffer, 10x (Sigma-Aldrich, catalog number: 20-188)

30. Laemmli buffer, $2 x$ (Bio-Rad, catalog number: 1610737)

31. $4-20 \%$ pre-casted gels (Bio-Rad, catalog number: 4561094$)$

32. ECL Prime Western blotting detection reagent (GE Healthcare Life Sciences, catalog number: RPN 2232) 
33. Tris Base (Fisher Scientific, catalog number: BP152-500)

34. Methanol (Sigma-Aldrich, catalog number: 34860-2L-R)

35. Uranyl Acetate powder (Electron Microscopy Sciences, catalog number: 22400)

36. Running buffer for Western Blotting (see Recipes)

37. Transfer buffer for Western Blotting (see Recipes)

38. $1 \%$ Uranyl Acetate solution (see Recipes)

\section{Equipment}

1. Optima ${ }^{T M}$ L-90K ultracentrifuge (Beckman Coulter, catalog number: 969349)

2. Fixed angle type 45 Ti rotor (Beckman Coulter, Brea, CA, catalog number: 339160)

3. $70 \mathrm{ml}$ Centrifuge bottles (Beckman Coulter, catalog number: 355655)

4. SW 41 Ti rotor, swinging bucket, titanium, $6 \times 13.2 \mathrm{ml}, 41,000 \mathrm{rpm}, 288,000 \times \mathrm{g}$ (Beckman Coulter, catalog number: 331362)

5. Thin wall, Ultra-Clear ${ }^{\top \mathrm{M}} 13.2 \mathrm{ml}, 14 \times 89 \mathrm{~mm}$ ultracentrifuge tubes (Beckman Coulter, catalog number: 344059)

6. Ultrasonic bath (Branson, catalog number: 3510MTH)

7. Transmission electron microscope (TEM, LEO 906E, Carl Zeiss, Germany)

8. Atomic force microscopy (AFM, Bruker Nano Surfaces, Santa Barbara, CA)

9. Electronic balance, readability: $0.01 \mathrm{mg}$ (OHAUS, model: EX125)

10. Particle size analyzer (Brookhaven Instruments Corporation, model: 90PLUS)

11. Semi-micro Cuvettes, Clear, $1.5 \mathrm{ml}$ (Sigma, Catalog number: BR759115)

12. Zetasizer (Malvern, Nano series, model: Nano-ZS90)

13. Disposable Capillary Cell (Malvern, Catalog number: DTS 1070 or DTS 1061)

14. Fluorometric microplate reader (BioTek, model: Synergy 2)

15. Western blot apparatus (BioRad, PowerPac ${ }^{\circledR}$ Basic power, and Mini-Protein ${ }^{\circledR}$ Electrophoresis chamber)

16. Milli-Q water purification system (Millipore, model: Advantage A10)

17. Ice bucket

18. Timer

\section{Software}

1. 90 Plus Particle Sizing Software (Brookhaven Instruments Corporation)

2. Malvern Zetasizer 


\section{Procedure}

A. Preparing the feces sample (selection of the mouse strain depends on the animal model of interest, in our case, we use C57BL/6, as DSS induced acute colitis in C57BL/6 is a well-established model)

1. Put $20 \mathrm{C} 57 \mathrm{BL} / 6$ mice to autoclaved mouse cages (without bedding, 5 per cage or one mouse per cage, depends on the experiment) or clean disposable paper boxes ( 5 per box or one mouse per box, depends on the experiment).

2. After 2 to $3 \mathrm{~h}$, collect all the feces.

3. Store the feces to $-20^{\circ} \mathrm{C}$ fridge if not use immediately. The fecal pellets can be stored for one week.

B. Isolating the total exosomes

1. Weigh the feces, add to a clean $50-\mathrm{ml}$ conical tube ( 1.0 gram of feces in each tube, roughly 50 to 75 fecal pellets.)

2. Take another clean $50-\mathrm{ml}$ conical tube, put five protease inhibitor cocktail tablets, add $50 \mathrm{ml}$ icecold PBS, shake until the tablets are dissolved.

3. Add $25 \mathrm{ml} \mathrm{PBS}$ solution prepared in Step B2 to the 50 - $\mathrm{ml}$ conical tube (contains 1.0-gram feces.)

4. Put the tube in the $4{ }^{\circ} \mathrm{C}$ fridge for $30 \mathrm{~min}$.

5. Take out the tube, vortex for 5 min at maximum speed.

Note: A simplified workflow for isolating exosomes from feces is shown in Figure 1. All the feces should be broken up into small particles (Figure 2).

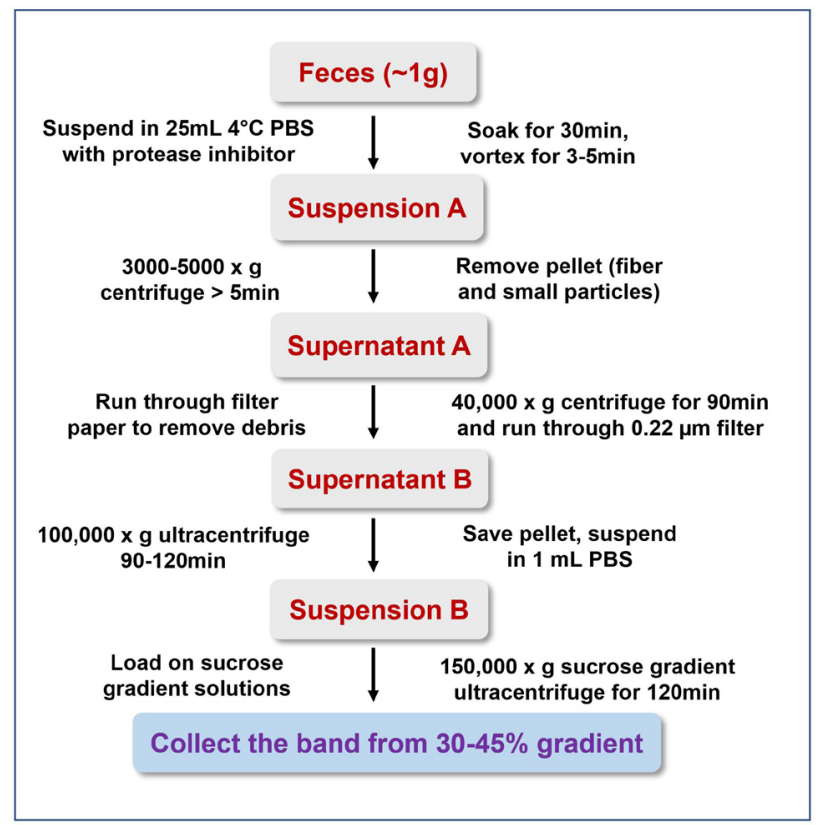

Figure 1. Simplified workflow for isolation exosomes from mouse feces 


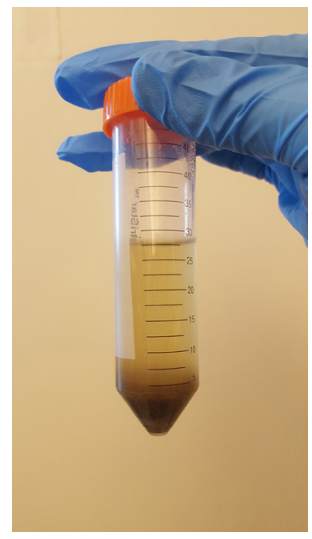

Figure 2. Fecal suspension after vortex

6. Centrifuge at $3,000 \times g$ for $10 \mathrm{~min}$ at $4{ }^{\circ} \mathrm{C}$, collect the supernatant.

7. Add $25 \mathrm{ml}$ PBS solution prepared in Step B2 to the remains of the $50-\mathrm{ml}$ conical tube.

8. Repeat Step B6.

9. Pool the supernatant.

10. Centrifuge at $3,000 \times g$ for $30 \mathrm{~min}$ at $4{ }^{\circ} \mathrm{C}$, collect the supernatant.

11. Set up a filtration device with a sterilized glass funnel, run the sample through filter paper to remove debris (Figure 3).

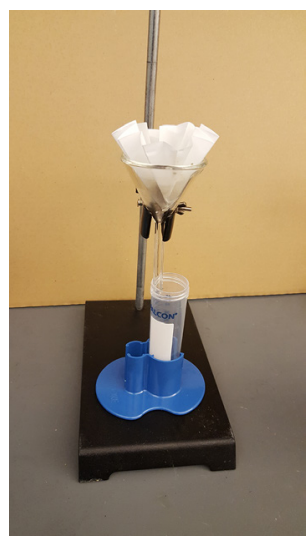

Figure 3. Paper filtration to remove the fecal debris

12. Centrifuge at $40,000 \times g$ for $1.5 \mathrm{~h}$ at $4{ }^{\circ} \mathrm{C}$, collect the supernatant. 


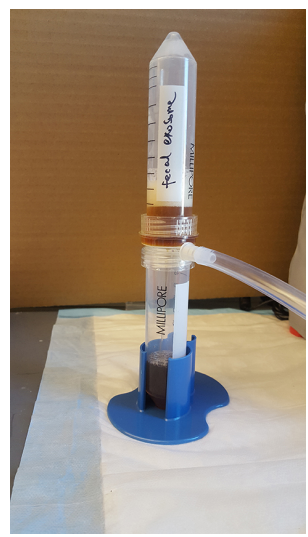

\section{Figure 4. Vacuum filtration to remove the microbes}

13. Run through a $0.22 \mu \mathrm{m}$ filter to remove microbes (Figure 4).

14. Centrifuge at $150,000 \times \mathrm{g}$ for $2.5 \mathrm{~h}$ at $4{ }^{\circ} \mathrm{C}$, discard the supernatant, and keep the visible pellet.

15. Wash the pellet three times with 1-2 ml PBS, centrifuge at $150,000 \times g$ for $10-15$ mins (at $4{ }^{\circ} \mathrm{C}$ ) between each wash and discard the first and second time's PBS, save the last time washing PBS as the exosome blank solution for protein quantitation.

16. Save the pellet (Figure 5).

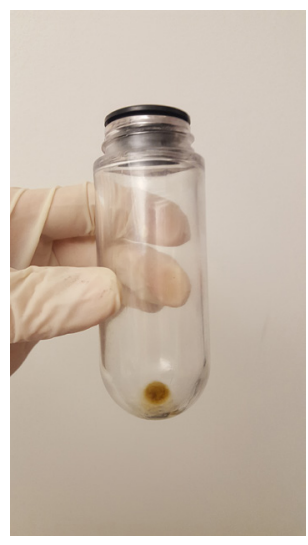

Figure 5. Exosome pellet after ultracentrifugation

17. Resuspend the pellet in PBS ( $1 \mathrm{ml}$ PBS per $1 \mathrm{~g}$ of feces sample).

18. Store the suspension in the $4{ }^{\circ} \mathrm{C}$ fridge before characterization.

Note: Store the samples at $-80^{\circ} \mathrm{C}$ if you do not test the sample in 2 days.

C. Subfractionation of total exosome (sucrose density gradient ultracentrifugation) to isolate colonic exosomes from microbiota-derived extracellular vesicles 
1. Load $60 \%$ sucrose solution

2. Load $45 \%$ sucrose solution

3. Load $30 \%$ sucrose solution

4. Load $8 \%$ sucrose solution

5. Load PBS on top of the solution

6. Load sample to the PBS layer

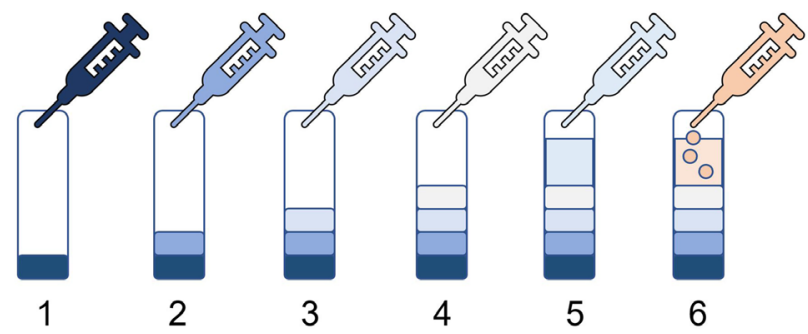

Figure 6. Setting up of the sucrose gradient

1. Make $8 \%, 30 \%, 45 \%, 60 \%(\mathrm{w} / \mathrm{v})$ sucrose solution in double distilled water and filtrate the solution through $0.22 \mu \mathrm{m}$ filter.

Note: Filter all the $8 \%, 30 \%, 45 \%, 60 \%$ sucrose solutions through $0.22 \mu$ m membrane to remove small particles before sample loading, small particles will contaminate the exosomes when doing ultracentrifugation.

2. Load the centrifuge tubes ( $14 \times 89 \mathrm{~mm}$ ) with sucrose solution, from $60 \%$ to $8 \%$, with $1.5 \mathrm{ml}$ of $60 \%, 1.5 \mathrm{ml}$ of $45 \%, 1.5 \mathrm{ml}$ of $30 \%, 1 \mathrm{ml}$ of $8 \%$, then $4.5 \mathrm{ml}$ of PBS (Figure 6 ).

3. Label the sample with dye (Ponceau S Solution, $1.0 \mathrm{ml}$ sample with $10 \mu \mathrm{l}$ dye).

4. Load labeled sample to the PBS layer.

5. Centrifuge at $150,000 \times g$ for $3 \mathrm{~h}$ at $4{ }^{\circ} \mathrm{C}$ (using SW41 rotor).

6. Remove the $8-30 \%$ layer by pipetting, use a glass pipette to collect the layer with dye $(30-45 \%$ layer, Figure 7), dilute the collected solution with PBS to 10 times volume.

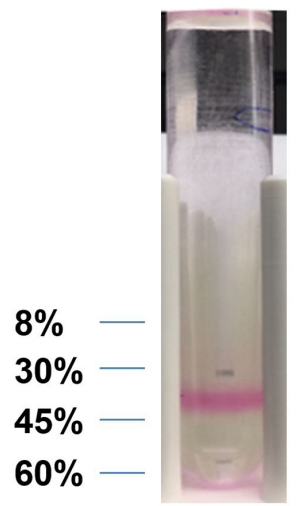

Figure 7. Labeled band of exosome 
7. Centrifuge at $150,000 \times g$ for $2 \mathrm{~h}$ at $4{ }^{\circ} \mathrm{C}$, save the pellet.

8. Re-suspend the pellet in $5 \mathrm{ml} \mathrm{PBS.}$

9. Store the suspension in the $4{ }^{\circ} \mathrm{C}$ fridge before characterization (see Note 1 ).

\section{Characterization}

D. Particle size and surface zeta potential

Note: Turn on the instrument (Particle size analyzer and Zetasizer) for at least 15 min before the size and zeta potential measurement.

1. Particle size measurement: Take $0.5 \mathrm{ml}$ exosome solution, dilute with $2.0 \mathrm{ml}$ PBS, pipette into a cuvette (avoid generating bubbles), insert cuvette to the chamber of particle size analyzer. Read the size of the particles by the 90 Plus Particle Sizing Software. The average size of the hydrated exosome is about $155 \mathrm{~nm}$ (152.8 to $157.9 \mathrm{~nm}$ in this test, see Note 2) in diameter (Figure 8).

2. Particle surface zeta potential measurement: Take a $0.8 \mathrm{ml}$ diluted solution (prepared for particle size measurement in Step D1), slowly pipette into a disposable capillary cell, cover the cell, insert the cell to the chamber of zeta analyzer, and record the value. The Z-potential of the sample is about $-11.2 \mathrm{mV}(-10.2$ to $-12.2 \mathrm{mv}$ in this test) at neutral $\mathrm{pH}$ (Figure 9, software: Malvern Zetasizer, see Note 2).

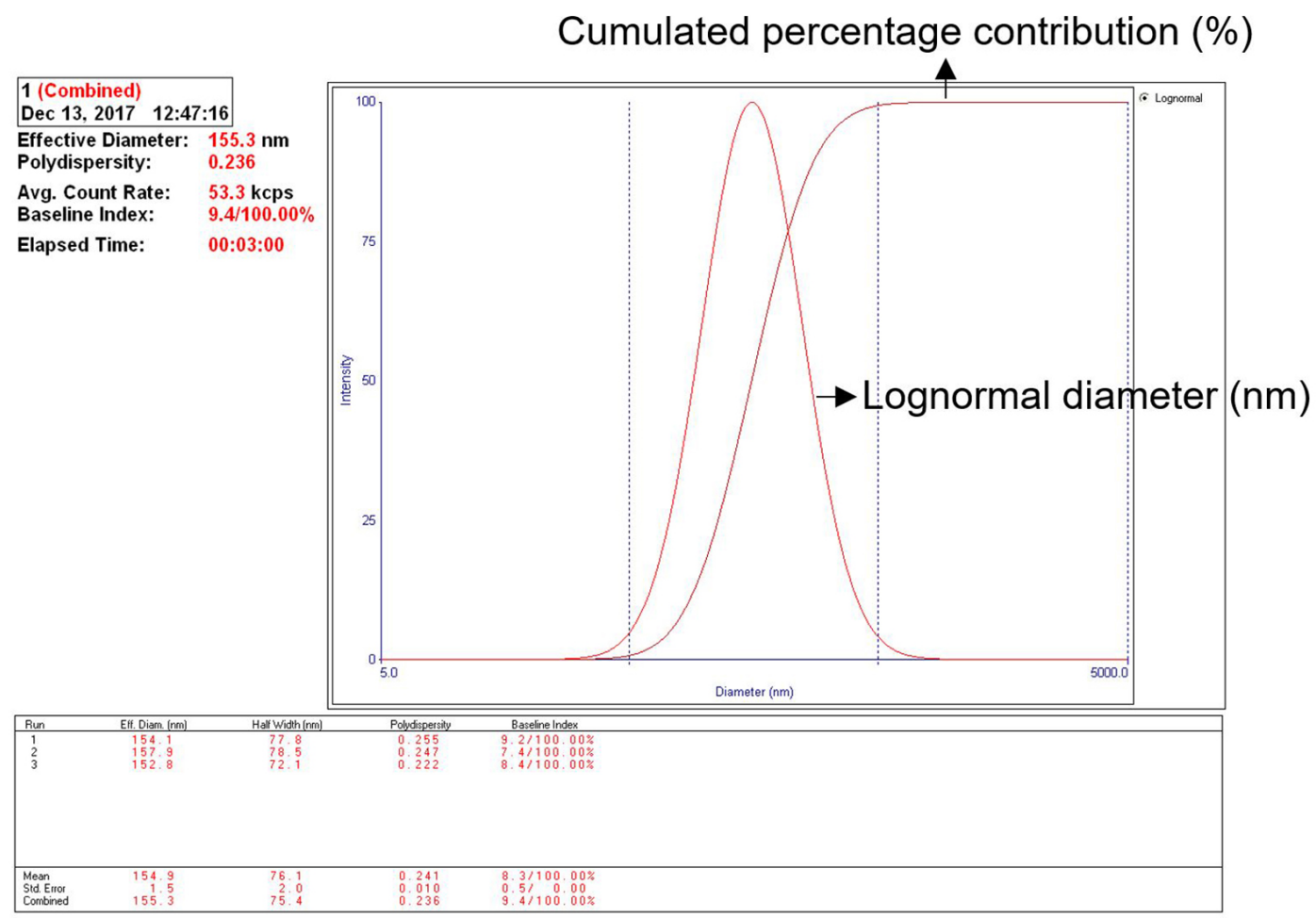

Figure 8. Particle size measurement of the hydrated fecal exosome 
Sample Name: 171214exosome011

SOP Name: mansettings.nano

File Name: 10-6-2017.dts

Dispersant Name: Water

Dispersant RI: 1.330

Record Number: 111

Date and Time: Thursday, December 14, 2017 2:34:38 PM

Viscosity (cP): 0.8872

Dispersant Dielectric Constant: 78.5

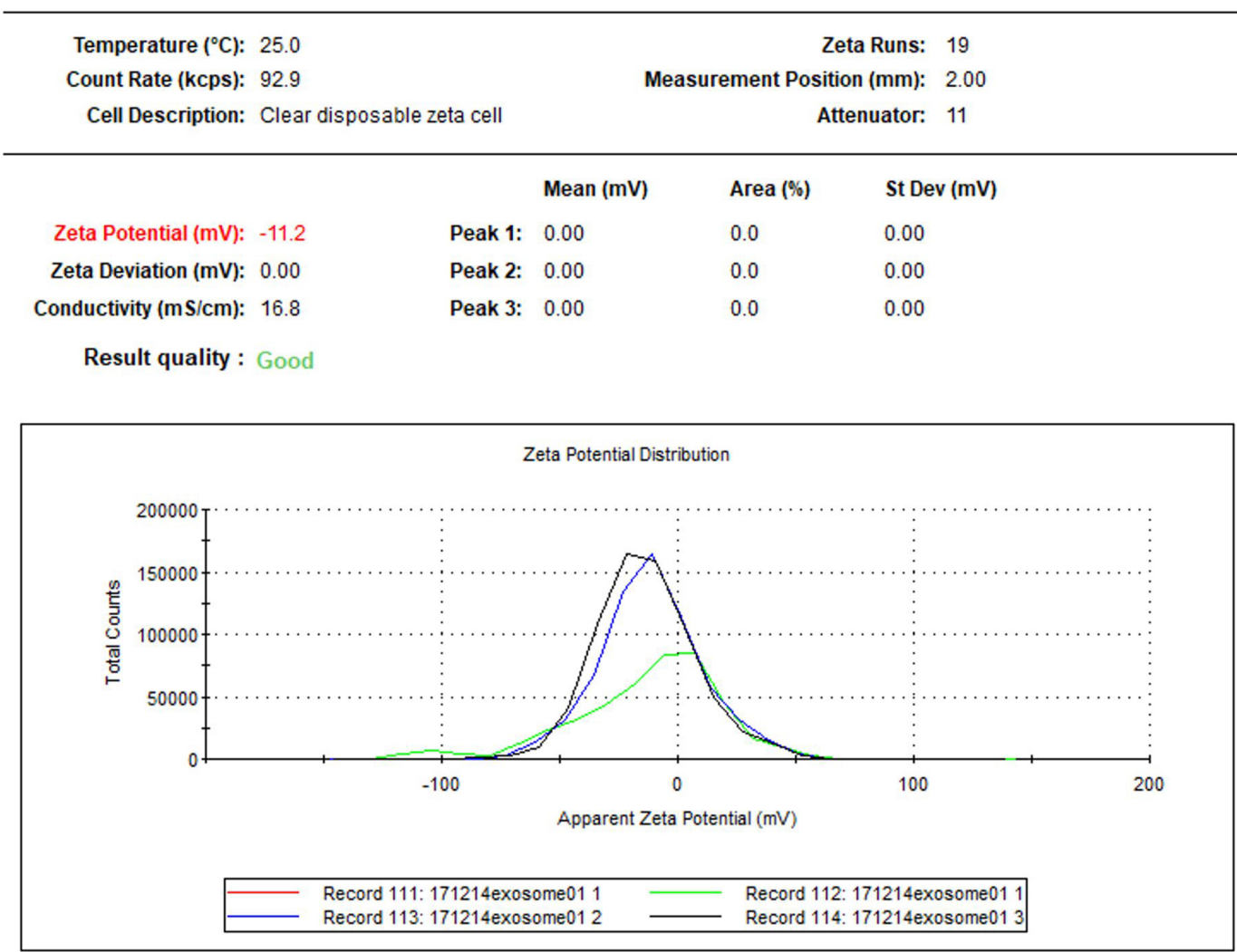

Figure 9. Zeta potential test of fecal exosomes

\section{E. Protein concentration}

1. Use the $D C^{T M}$ Protein assay reagent kit. Add $20 \mu \mathrm{l}$ of reagent $S$ to each $\mathrm{ml}$ of reagent $A$.

2. Prepare a protein standard curve containing $0.25,0.50,0.75,1.0,1.25,1.50 \mathrm{mg} / \mathrm{ml} \mathrm{BSA}$ in $1 \mathrm{x}$ PBS.

3. Pipet $5 \mu \mathrm{l}$ of standards and samples into a clean 96 -well plate.

4. Add $25 \mu$ l of reagent $A^{\prime}(1 \mathrm{ml}$ reagent $A$ and $20 \mu$ l of reagent $S$ ) into each well.

5. Add $200 \mu \mathrm{l}$ reagent $B$ into each well. Mix by pipetting up and down three times.

6. Wait for $15 \mathrm{~min}$ at room temperature.

7. Read the absorbance at $750 \mathrm{~nm}$ by a microplate reader.

8. Draw the standard curve and calculate the protein concentration.

Note: Expected protein concentration is between 0.25 to $1.5 \mathrm{mg} / \mathrm{ml}$ for exosomes isolated from $1 \mathrm{~g}$ of feces as starting material. If the concentration is beyond the linear range $(0.25$ to $1.5 \mathrm{mg} / \mathrm{ml}$, see Figure 13 and Table 1), dilute or concentrate the sample and redo the test. 
F. CD-63 protein detection (Western Blotting method)

1. Add $100 \mu \mathrm{l}$ RIPA buffer (10x) to $900 \mu$ icy cold PBS (containing protease inhibitor cocktail (Roche)) to make a $1 \mathrm{ml}$ solution $A$.

2. Take $20 \mu \mathrm{g}$ fecal nanovesicles ( $20 \mu \mathrm{l}$ from $1 \mathrm{mg} / \mathrm{ml}$ solution), add $100 \mu \mathrm{l}$ icy cold solution $\mathrm{A}$.

3. Sonicate the sample for 3 times at $42 \mathrm{kHz}$, room temperature, $10-15 \mathrm{~s}$ each time.

4. Spin at $16,000 \times g$ for $20 \mathrm{~min}$ at $4{ }^{\circ} \mathrm{C}$.

5. Take the supernatant, add the same volume of Laemmli buffer $(2 x)$.

6. Boil the samples at $95^{\circ} \mathrm{C}$ for $5 \mathrm{~min}$.

7. Centrifuge at $16,000 \times g$ in a microcentrifuge for $1 \mathrm{~min}$.

8. Load the sample on $4-20 \%$ pre-casted gel.

9. Add running buffer (Recipe 1), run the gel for $5 \mathrm{~min}$ at $50 \mathrm{v}$.

10. Increase the voltage to $100 \mathrm{v}$, run the gel for $1 \mathrm{~h}$.

11. Take out the gel, add transfer buffer (Recipe 2), adjust the voltage to $100 \mathrm{v}$, and transfer to nitrocellulose membranes (Chankova et al., 2013).

12. Take out the nitrocellulose membrane, block with $5 \%$ non-fat milk at room temperature for $1 \mathrm{~h}$.

13. Add primary antibody (Anti-CD63 1:200 dilution in PBS, and Anti-beta-actin, 1:200 dilution in PBS), incubate for $2 \mathrm{~h}$ at room temperature.

14. Wash 3-5 times with PBS for 5 mins, add the secondary HRP-conjugated antibody and incubate for $2 \mathrm{~h}$ at room temperature.

15. Detect the chemiluminescence bands with ECL Plus reagent. A representative western blotting picture is shown in Figure 10.

$$
\begin{aligned}
& \text { Loading }(\mu \mathrm{g}) \quad \begin{array}{lll}
10 \quad 20 \quad 40 & \frac{\text { Large intestine }}{10}
\end{array} \\
& \begin{aligned}
& \leftarrow \text { CD63 } \\
&- \text { Beta-Actin }
\end{aligned}
\end{aligned}
$$

Figure 10. Western blot band of CD63 (use lysed mouse large intestine sample as control)

G. Transmission electron microscopy (TEM)

1. Pipette $1 \mu \mathrm{g}(1 \mu \mathrm{l}$ of $1 \mathrm{mg} / \mathrm{ml})$ fecal exosome solution in $10 \mu \mathrm{l}$ distilled water.

2. Deposit 5 to $10 \mu \mathrm{l}$ sample onto the surface of Formvar ${ }^{\circledR}$-coated copper grids.

3. Add $5 \mu \mathrm{l} 1 \%$ uranyl acetate (Recipe 3 ) for $15 \mathrm{~s}$.

4. Dry the sample at room temperature for at least 30 mins.

5. Test the sample by the transmission electron microscopy. A representative TEM picture of the fecal exosome is shown in Figure 11. 


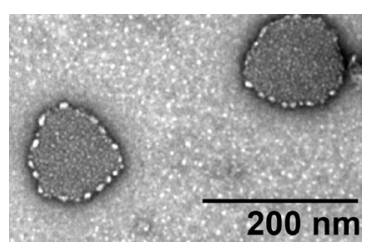

Figure 11. TEM graph of the isolated fecal exosome

H. Atomic force microscopy (AFM)

1. Pipette $0.25 \mu \mathrm{g}(0.5 \mu \mathrm{l}$ of $0.5 \mathrm{mg} / \mathrm{ml})$ fecal exosome solution in $10 \mu \mathrm{l}$ PBS.

2. Deposit the 5 to $10 \mu \mathrm{l}$ sample onto a mica sheet.

3. Dry the sample at room temperature for about $2 \mathrm{~h}$.

4. Add $20 \mu \mathrm{l}$ distilled water to the mica sheet.

5. Dry the sample at room temperature for another $2 \mathrm{~h}$.

6. Wait until the sample is relatively flat.

7. Scan the sample with an area about $4 \times 4 \mu \mathrm{m}$ or a smaller area with 2-50 $\mathrm{nm}$ in height. A typical AFM graph of the fecal exosome is shown in Figure 12.
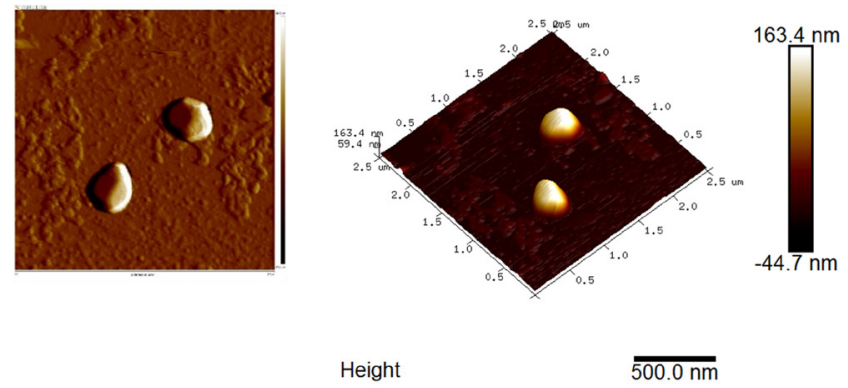

Figure 12. AFM graph of the isolated fecal exosome

\section{Data analysis}

Table 1 is a typical data analysis for the exosome sample's protein concentration test; quantification is based on the standard curve of BSA samples; this is as described in "Section E. Protein concentration".

1. Subtract the averaged blank PBS value from the standards values, (or select the "subtract blank value function" in the plate reader's software and take the value directly).

2. Take the average value of adjusted standards and make a regression equation in Microsoft Excel, calculate the correlation coefficient ( $\mathrm{R}$ or $\mathrm{R}$ square), make sure the correlation coefficient is above 0.95 (Figure 13).

3. Adjust the exosome sample's value by subtracting the averaged exosome blank's (PBS) value. Take the average of the adjusted exosome sample's values, and substitute into the regression equation as " $y$ " (OD 750), calculate the value of " $x$ ", which is the protein concentration. 
4. Last, normalize the protein concentration as "mg per gram of feces" by multiplying the dilution factor. $(2 \mathrm{x}$ dilution means $1 \mathrm{~g}$ of feces in $2 \mathrm{ml}$ PBS, $0.5 \mathrm{x}$ dilution means $1 \mathrm{~g}$ of feces in $0.5 \mathrm{ml}$ PBS. See Note 1).

Standard Curve of Protein Quantitation

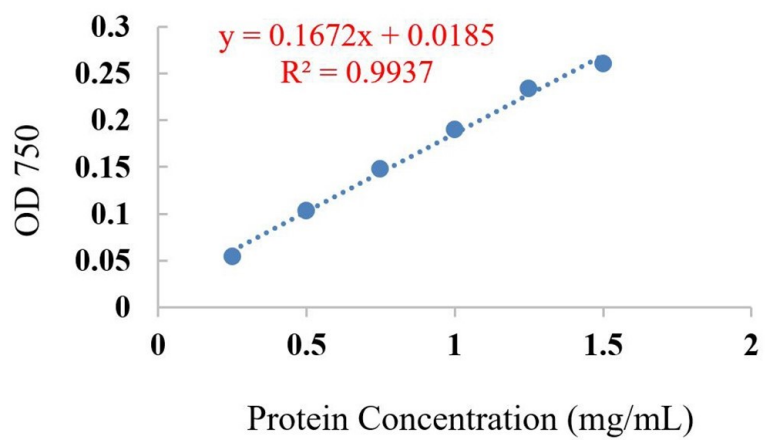

\begin{tabular}{|l|l|}
\hline $\begin{array}{l}\text { Protein } \\
\mathrm{mg} / \mathrm{mL}\end{array}$ & $\begin{array}{l}\text { OD } 750 \text { value } \\
\text { (Average) }\end{array}$ \\
\hline 0.25 & 0.0545 \\
0.5 & 0.103 \\
0.75 & 0.1475 \\
1 & 0.19 \\
1.25 & 0.234 \\
1.5 & 0.26 \\
\hline
\end{tabular}

Figure 13. Standard curve and regression equation for $\mathrm{DC}^{\mathrm{TM}}$ protein concentration test

Table 1. Protein quantitation of fecal exosome samples

\begin{tabular}{|c|c|c|c|c|c|c|}
\hline \multirow{2}{*}{$\begin{array}{l}\text { Standards } \\
\text { (BSA) }\end{array}$} & \multicolumn{6}{|c|}{ Concentration (mg/ml) } \\
\hline & 0.25 & 0.5 & 0.75 & 1.0 & 1.25 & 1.5 \\
\hline & \multicolumn{6}{|c|}{ OD750 value } \\
\hline Standards 1 & 0.115 & 0.166 & 0.208 & 0.257 & 0.297 & 0.328 \\
\hline Standards 2 & 0.125 & 0.171 & 0.219 & 0.254 & 0.303 & 0.324 \\
\hline Blank (PBS) & 0.065 & 0.066 & 0.067 & 0.067 & 0.065 & 0.065 \\
\hline Blank (Average) & \multicolumn{6}{|l|}{0.066} \\
\hline Standards 1 minus Blank & 0.050 & 0.101 & 0.142 & 0.191 & 0.231 & 0.262 \\
\hline Standards 2 minus Blank & 0.059 & 0.105 & 0.153 & 0.189 & 0.237 & 0.258 \\
\hline Standards minus Blank (Average) & 0.055 & 0.103 & 0.148 & 0.190 & 0.234 & 0.260 \\
\hline Standard curve & \multicolumn{6}{|c|}{$Y=0.1672 x+0.0185\left(R^{2}=0.9937\right)$} \\
\hline Exosome Blank* & \multirow{2}{*}{\multicolumn{2}{|c|}{0.072}} & \multicolumn{2}{|l|}{0.076} & \multicolumn{2}{|l|}{0.075} \\
\hline Blank (Average) & & & \multicolumn{2}{|l|}{0.074} & & \\
\hline Exosome sample 1 & \multicolumn{2}{|l|}{0.219} & \multicolumn{2}{|l|}{0.223} & \multicolumn{2}{|l|}{0.212} \\
\hline Sample 1 minus Blank & \multicolumn{2}{|l|}{0.145} & \multicolumn{2}{|l|}{0.149} & \multicolumn{2}{|l|}{0.138} \\
\hline Sample 1 concentration & \multicolumn{6}{|c|}{$0.750 \mathrm{mg} / \mathrm{ml}$} \\
\hline Normalized concentration ( $2 x$ dilution) & \multicolumn{6}{|c|}{$1.500 \mathrm{mg} / \mathrm{g}$} \\
\hline Exosome sample 2 & \multicolumn{2}{|l|}{0.188} & \multicolumn{2}{|l|}{0.201} & \multicolumn{2}{|l|}{0.202} \\
\hline Sample 2 minus Blank & \multicolumn{2}{|l|}{0.114} & \multicolumn{2}{|l|}{0.127} & \multicolumn{2}{|l|}{0.128} \\
\hline Sample 2 concentration & \multicolumn{6}{|c|}{$0.630 \mathrm{mg} / \mathrm{ml}$} \\
\hline Normalized concentration ( $2 x$ dilution) & \multicolumn{6}{|c|}{$1.260 \mathrm{mg} / \mathrm{g}$} \\
\hline Exosome sample 3 & \multicolumn{2}{|l|}{0.178} & \multicolumn{2}{|l|}{0.178} & \multicolumn{2}{|l|}{0.176} \\
\hline Sample 3 minus Blank & \multicolumn{2}{|l|}{0.104} & \multicolumn{2}{|l|}{0.104} & \multicolumn{2}{|l|}{0.102} \\
\hline Sample 3 concentration & \multicolumn{4}{|c|}{$0.510 \mathrm{mg} / \mathrm{ml}$} & & \\
\hline Normalized concentration ( $0.5 x$ dilution) & \multicolumn{6}{|c|}{$0.26 \mathrm{mg} / \mathrm{g}$} \\
\hline
\end{tabular}




\section{$\underline{\text { Notes }}$}

1. The yield of total exosome before sucrose density gradient ultracentrifugation is about $0.8-2.0$ mg per gram of feces, the yield of exosome sub-fraction from $30-45 \%$ sucrose density is around 0.1-0.3 mg per gram of feces. The quantitation is performed by the protein quantitation method.

2. The size of isolated fecal exosomes may vary from 125 to $170 \mathrm{~nm}$; Surface zeta potential range may vary from -14.0 to $-9.0 \mathrm{mv}$.

\section{$\underline{\text { Recipes }}$}

1. Running buffer for Western Blotting ( $\mathrm{pH} 8.3$, store in $4{ }^{\circ} \mathrm{C}$, shelf life: 3 months)

$25 \mathrm{mM}$ Tris

$190 \mathrm{mM}$ glycine

$0.1 \% \mathrm{w} / \mathrm{v}$ SDS in distilled water

2. Transfer buffer for Western Blotting ( $\mathrm{pH} 8.3$, store in $4^{\circ} \mathrm{C}$, shelf life: 3 months)

$25 \mathrm{mM}$ Tris

$190 \mathrm{mM}$ glycine

$20 \% \mathrm{v} / \mathrm{v}$ methanol in distilled water

3. $1 \%$ Uranyl Acetate solution ( $\mathrm{pH} 4.5$, store in $4{ }^{\circ} \mathrm{C}$, shelf life: 3 months)

a. Use prepared 4\% Uranyl Acetate stock solution: 4 grams Uranyl Acetate powder dissolved in $100 \mathrm{ml}$ preheated milli-Q filtered water $\left(50-60{ }^{\circ} \mathrm{C}\right)$

b. Mix $1 \mathrm{ml} 4 \%$ stock solution with $3 \mathrm{ml}$ of Milli-Q filtered water

\section{Acknowledgments}

This work was supported by the National Institute of Diabetes and Digestive and Kidney Diseases (RO1-DK-116306 and RO1-DK-107739 to D.M.) and the Department of Veterans Affairs (Merit Award BX002526 to D.M.). D.M. is a recipient of a Senior Research Career Scientist Award (BX004476) from the Department of Veterans Affairs. This protocol was used in a recently published work by Chunhua Yang (Yang et al., 2019).

\section{Competing interests}

The authors declare no conflicts of interest within the work.

\section{References}

1. Chankova, S., Mitrovska, Z. and Yurina, N. (2013). Western blot analysis of chloroplast HSP70B in chlorella species. Bio-protocol 3(15): e850. 
2. Deng, Z. B., Zhuang, X., Ju, S., Xiang, X., Mu, J., Liu, Y., Jiang, H., Zhang, L., Mobley, J., McClain, C., Feng, W., Grizzle, W., Yan, J., Miller, D., Kronenberg, M. and Zhang, H. G. (2013). Exosome-like nanoparticles from intestinal mucosal cells carry prostaglandin E2 and suppress activation of liver NKT cells. J Immunol 190(7): 3579-3589.

3. Gallart-Palau, X., Serra, A. and Sze, S. K. (2016). Enrichment of extracellular vesicles from tissues of the central nervous system by PROSPR. Mol Neurodegener 11(1): 41.

4. Johnsen, K. B., Gudbergsson, J. M., Skov, M. N., Pilgaard, L., Moos, T. and Duroux, M. (2014). A comprehensive overview of exosomes as drug delivery vehicles - endogenous nanocarriers for targeted cancer therapy. Biochim Biophys Acta 1846(1): 75-87.

5. Kim, S. M. and Kim, H. S. (2018). Engineering of extracellular vesicles as drug delivery vehicles. Stem Cell Investig 5(5): 74-85.

6. Knepper, M. A. and Pisitkun, T. (2007). Exosomes in urine: who would have thought...? Kidney Int 72(9): 1043-1045.

7. Koga, Y., Yasunaga, M., Moriya, Y., Akasu, T., Fujita, S., Yamamoto, S. and Matsumura, Y. (2011). Exosome can prevent RNase from degrading microRNA in feces. $J$ Gastrointest Oncol 2(4): 215-222.

8. Motamedinia, P., Scott, A. N., Bate, K. L., Sadeghi, N., Salazar, G., Shapiro, E., Ahn, J., Lipsky, M., Lin, J., Hruby, G. W., Badani, K. K., Petrylak, D. P., Benson, M. C., Donovan, M. J., Comper, W. D., McKiernan, J. M. and Russo, L. M. (2016). Urine exosomes for non-invasive assessment of gene expression and mutations of prostate cancer. PLoS One 11(5): e0154507.

9. Sun, D., Zhuang, X., Xiang, X., Liu, Y., Zhang, S., Liu, C., Barnes, S., Grizzle, W., Miller, D. and Zhang, H. G. (2010). A novel nanoparticle drug delivery system: the anti-inflammatory activity of curcumin is enhanced when encapsulated in exosomes. Mol Ther 18(9): 1606-1614.

10. Vella, L. J., Scicluna, B. J., Cheng, L., Bawden, E. G., Masters, C. L., Ang, C. S., Willamson, N., McLean, C., Barnham, K. J. and Hill, A. F. (2017). A rigorous method to enrich for exosomes from brain tissue. $J$ Extracell Vesicles 6(1): 1348885.

11. Wang, J., Zheng, Y. and Zhao, M. (2016). Exosome-based cancer therapy: implication for targeting cancer stem cells. Front Pharmacol 7: 533.

12. Wu, M., Ouyang, Y., Wang, Z., Zhang, R., Huang, P. H., Chen, C., Li, H., Li, P., Quinn, D., Dao, M., Suresh, S., Sadovsky, Y. and Huang, T. J. (2017). Isolation of exosomes from whole blood by integrating acoustics and microfluidics. Proc Natl Acad Sci U S A 114(40): 10584-10589.

13. Yang, C., Zhang, M., Sung, J., Wang, L., Jung, Y. and Merlin, D. (2019). Autologous exosome transfer: A new personalized treatment concept to prevent colitis in a murine model. $J$ Crohns Colitis.

14. Yeo, R. W., Lai, R. C., Zhang, B., Tan, S. S., Yin, Y., Teh, B. J. and Lim, S. K. (2013). Mesenchymal stem cell: an efficient mass producer of exosomes for drug delivery. Adv Drug Deliv Rev 65(3): 336-341. 